\title{
Editorial
}

\section{Dezentrale Abwasserbewirtschaftung}

Die Abwasserbewirtschaftung im ländlichen Raum ist für Österreich von großer Bedeutung. Diese umfasst zum einen die klassische Abwasserreinigung mit dezentralen Kläranlagen - von Kleinkläranlagen und kleinen Kläranlagen bis zu mittleren Anlagen auf Verbandsebene. Dazu gehört auch die Entsorgung/Verwertung von Klärschlamm, die im ländlichen Raum immer wichtiger wird, da die landwirtschaftliche Verwertung immer mehr zurückgedrängt wird. Zum anderen kommt die Bewirtschaftung von Niederschlagswasser durch Siedlungserweiterungen und die erwartete Zunahme der Starkregenereignisse in Anzahl und Intensität immer mehr in den Fokus und wird auch in naher und mittlerer Zukunft ein sehr wichtiges Thema bleiben.

Die vorliegende Ausgabe der Österreichischen Wasser- und Abfallwirtschaft befasst sich in vielfältiger Weise mit der dezentralen Abwasserbewirtschaftung. Im ersten Beitrag werden die Entwicklung, der Bestand und das Management von Kleinkläranlagen in Österreich beschrieben. Mit dieser Arbeit gibt es zum ersten Mal einen fundierten Überblick über Kleinkläranlagen in Österreich. Die Daten zu diesen werden in Österreich dezentral in den Bundesländern gesammelt und wurden erstmals bundesweit zusammengestellt. Der zweite Beitrag befasst sich mit der Weiterentwicklung eines speziellen Verfahrens zur Reinigung von Trübwasser, damit es auch für kleinere Kläranlagen einsetzbar wird. Ein weiterer Beitrag befasst sich mit der zukünftigen Klärschlammverwertung in Österreich. Das Ziel, $85 \%$ des kommunalen Klärschlammanfalls bis 2030 einer Monoverbrennung zuzuführen, ist eine interdisziplinäre Herausforderung. Der Beitrag weist auf den zur bestmöglichen Nutzung der Ressource Klärschlamm nötigen v. a. übergeordneten Planungsbedarf hin. Die letzten beiden Beiträge befassen sich mit der Bewirtschaftung von Niederschlagswasser. Zuerst wird dabei die dezentrale Versickerung von Straßenabwässern behandelt. Der letzte Beitrag untersucht die Auswirkung von Siedlungsstrukturen auf die Möglichkeiten und Potenziale dezentraler Niederschlagswasserbewirtschaftung.

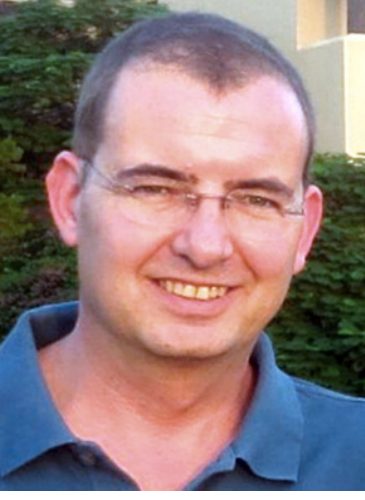

PD DI Dr. Günter Langergraber

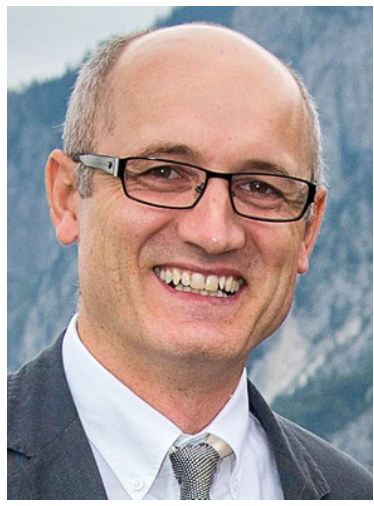

Univ.-Prof. DI Dr. Thomas Ertl

PD DI Dr. G. Langergraber ( $ه) \cdot$ Univ.-

\section{Prof. DI Dr. T. Ertl}

Department Wasser-Atmosphäre-

Umwelt, Institut für Siedlungswas-

serbau, Industriewasserwirtschaft

und Gewässerschutz, Universität für

Bodenkultur Wien,

Muthgasse 18,

1190 Wien, Österreich

guenter.langergraber@boku.ac.at

Univ.-Prof. DI Dr. T. Ertl

thomas.ert|@boku.ac.at 